\title{
Nose stars and brain stripes
}

SIR - Mammals with sensory receptor specializations often have corresponding modifications in the brain that help us understand general principles of brain organization. A conspicuous and unique specialization is the star of the star-nosed mole's face, where 11 fleshy rays branch out from each side of the nose ( $a$ in the figure). Each ray is covered with domes

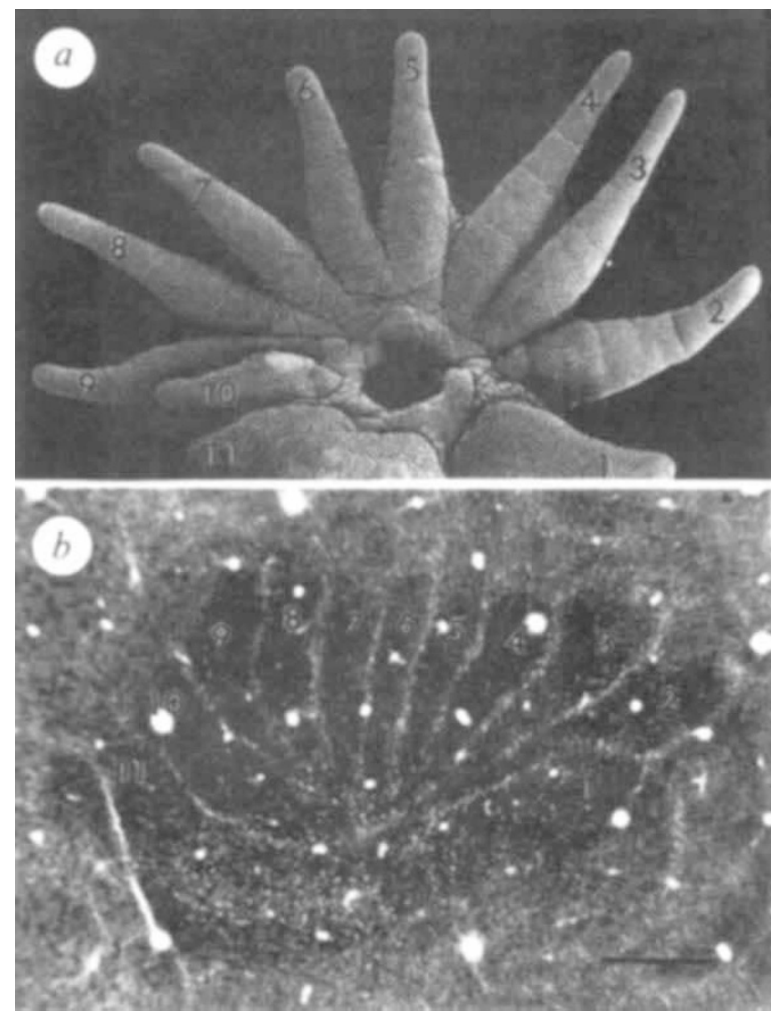

a, A rotated face-on view of the right half of the numbered fleshy rays of the nose surrounding the nostril. Up is right. $b$, An example of a brain section cut parallel to the surface of the somatosensory cortex and processed for cytochrome oxidase. The pattern of numbered ray-like stripes of darkly stained tissue is isomorphic with the rays of the contralateral half of the nose. Scale bar, $0.5 \mathrm{~mm}$. Medial, up; posterior, right.

that cap underlying arrays of receptors and nerve endings called Eimer's organs ${ }^{1}$. The rays are in constant motion and are repeatedly brought into contact with the substrate as the mole searches for food, thus seeming to be an important source of information about the external world. We expected this strange modification of the tactile surface of the nose to be reflected in the organization of the primary somatosensory cortex (S1), much as the sensory inputs from the whiskers of the face of rats and mice are expressed in a dot-like pattern of cortical 'barrels'2. However, we expected the morphological units, if apparent, to be shaped like rays rather than hair follicles.

To test our assumptions, we identified parts of the somatosensory cortex responding to stimulating rays in five anaes- thetized star-nosed moles (Condylura cristata) by making small openings in the skull and recording the responses of neurons with microelectrodes. Sites where neurons responded vigorously to light touch on specific rays were marked with small electrolytic lesions. The anaesthetized moles were perfused with saline and fixatives, and cerebral cortex removed, flattened, frozen and cut parallel to the surface into $60-\mu \mathrm{m}$ sections. Brain sections were processed for cytochrome oxidase, which enhances the barrels of somatosensory cortex of rats and mice ${ }^{3}$. In all processed hemispheres, 11 dark stripes of cytochrome oxidase-dense tissue separated by narrow septa of cytochrome oxidase-light tissue were apparent in S1. Most of the pattern appeared in single favourable sections from the flattened cortex ( $b$ in the figure), and the full pattern could be reconstructed from several adjoining sections. Because the number of stripes in S1 of each hemisphere conforms to the number of rays on each side of the face, and marking microlesions related most of the stripes to specific rays, we propose that each stripe represents the sensory input from a given ray in an isomorphic pattern.

The stripes of $\mathrm{S} 1$ of the star-nosed mole constitute a second dramatic example of how somatosensory cortex can be divided into distinct morphological structures, each devoted to a specific body part. The other well-known example is the dot-like barrel field of $\mathrm{S} 1$ in rats, mice and some marsupials ${ }^{2-4}$, where cytochrome oxidasedense barrels of cells represent the vibrissae of the upper face. We believe that these patterns are explicit expressions of a widespread tendency for sensory inputs differing in neural activity patterns to be segregated in the brain ${ }^{5}$. Hints of morphologically distinct septa between representations of major body parts are apparent in S1 of some primates, but such

\footnotetext{
1. Quilian, T. A. J. Zool. 149, 76-88(1966).

2. Woolsey, T. A., Welker, C. \& Schwartz, R. H. J. comp. Neurol. 164, 79-94 (1975)

3. Wong-Riley, M. T. T. \& Welt, C. Proc. natn. Acad. Sci. U.S.A. 77. 2333-2337 (1980)

4. Welker, W. I. \& Johnson, J. I.J. Anat. 99, 761-790 (1965)

5. Kaas, J. H. in Neurobiology of Neocortex (eds Rakic, P. \&
} Singer, W.) 101-113 (Wiley, New York, 1988). delimiting septa may be less apparent in larger-brained mammals, where neurons are less densely packed and peripheral specializations less pronounced.

\section{Kenneth C. Catania}

R. Glenn Northcutt

Department of Neuroscience,

University of California.

San Diego, California 92093, USA

Jon H. Kaas

Pam D. Beck

Department of Psychology,

Vanderbilt University,

Nashville, Tennessee 37240, USA

\section{Cytokine-antigen vaccines}

SIR - We read with interest the report of Tao and Levy ${ }^{1}$ on the effectiveness of an idiotype/GMCSF fusion protein as a vaccine. We have produced a similar antigencytokine vaccine, using less elegant techniques but nevertheless with success. Interferon- $\gamma$ is an effective adjuvant when administered simply mixed with an antigen ${ }^{2,3}$, but when we biotinylated it, and used avidin as an antigen, the cytokine-antigen conjugates were more immunogenic than simple mixtures or conjugates with inactivated cytokine. This success led us to suggest the potential of cytokine-antigen fusion proteins as vaccines $^{4}$. It appears that, at least in our case, the cytokine-antigen vaccine was more effective than the mixture not because of improved contact between antigen-presenting cells and the cytokine (as higher doses of the cytokine did not have the same effect) but perhaps because the cytokine was focused on cells presenting the antigen rather than on others presenting irrelevant antigens.

Whatever the mechanism involved, it seems that vaccines may need to contain elements to direct them to the appropriate antigen-presenting cell, and other elements to enhance antigen presentation by those cells, and/or to push the immune system in the required direction, for example to $\mathrm{Th} 1$ rather than $\mathrm{Th} 2$ responses ${ }^{5.6}$.

A. W. Heath

DNAX Research Institute,

901 California Ave

Palo Alto, California 94303, USA

J. H. L. Playfair

University College Medical School,

40-50 Tottenham St,

London W1P 9PG, UK

1. Tao, M. H. \& Levy, R. Nature 362, 755-758 (1993). 2. Playfair, J. H. L. \& de Souza, J. B. Clin. exp. Immun. 67 5-10 (1987)

3. Heath, A. W. Devey, M. E., Brown, I. N. Richards, C.E. \& Playfair, J. H. L. Immunology 67, 520-524 (1989).

4. Heath, A. W. \& Playfair, J. H. L. Immunology 71, 454-456 (1990).

5. Heath, A. W. \& Playfair, J. H. L. Vaccines'91, 351-354 (Cold Spring Harbor Laboratory Press, New York, 1991)

6. Hsieh. C.-S. etal. Science 260, 547-549 (1993). 